JKKP : Jurnal Kesejahteraan Keluarga dan Pendidikan http://doi.org/10.21009/JKKP

DOI: doi.org/10.21009/JKKP.041.01

E-ISSN : 2597-4521

\title{
HUBUNGAN KELEKATAN ORANG TUA DENGAN KEMANDIRIAN REMAJ A
}

\author{
Syifa Maulida ${ }^{1, a)}$, Nurlaila ${ }^{1, b)}$, Uswatun Hasanah ${ }^{1, c)}$ \\ a)syifamaulida0608@gmail.com, b)laila.mashabi@yahoo.com, c)uswatun-hasanah@unj.ac.id
}

1)P endidikan Kesejahteraan Keluarga

Fakultas Teknik Universitas Negeri J akarta

J I.Rawamangun Muka J akarta Timur 13220

\begin{abstract}
Abstrak
Kemandirian pada remaja lebih bersifat psikologis seperti adanya tanggung jawab, percaya diri, membuat keputusan sendiri, dan kebebasan berprilaku sesuai dengan keinginannya. Hal ini menjadi tugas bagi orangtua untuk dapat menumbuhkan kemandirian pada remaja, melalui kelekatan yang baik dalam keluarga. Penelitian ini bertujuan mencari hubungan kelekatan orangtua dengan kemandirian remaja. Penelitian ini dilaksanakan di SMPN 2 Bogor. Metode penelitian yang digunakan adalah survey. Populasi pada penelitian ini adalah remaja siswa/i kelas VIII SMPN 2 Bogor yang berjumlah 310 orang. Sampel yang digunakan sebanyak 175 orang dari populasi remaja siswa/i kelas VIII SMPN 2 Bogor. Uji hipotesis data yang digunakan dalam penelitian ini adalah Korelasi Koefesien Product Moment yang menyatakan korelasinya sebesar $r=0,148$ yang artinya hubungan antara variabel sangat lemah. Hasil Uji Signifikasi pada koefisiennya sebesar $t=1,980$ dan dapat disimpulkan bahwa koefisien korelasi adalah signifikan. Koefisien deterinasi yang diperoleh sebesar 2,21\% menunjukan variabel Kemandirian Remaja ditentukan oleh Kelekatan orangtua. Hasil hipotesis penelitian dan uji mengenai hubungan dapat diperoleh bahwa terdapat hubungan yang positif antara kelekatan orangtua dengan kemandirian remaja pada siswa/i SMPN 2 Bogor.
\end{abstract}

Kata kunci: Kelekatan Orangtua, Kemandirian Remaja

\section{THE ATTACHMENT PARENTS WITH INDEPENDENCE TEENAGERS}

\begin{abstract}
Independence in teenagers more psychological as the responsibility, confident, make your own decisions, and freedom pretending to according to her. So, it will be homework for their parents to make a best independence teenagers from attachment at their family. This research aims to find the relations the attachment parents with independence teenagers his research was conducted SMPN 2 Bogor. The methodology used is survey. The population in research is students VIII class of SMPN 2 Bogor. The hypothesis data used the research is a correlation the Coefficient Product Moment, that correlation of $r=0,148$ which means correlation the relation between variables are weak. The result from the coefficient significance is $t=1,980$ and can be concluded that the correlation coefficient is significant. The coefficient determination obtained $2,21 \%$, this showed variable independence teenagers by the attachment parents. The hypohesis research and test on relationship can be obtained that there is a positive relations between the attachment parents with independence teenagers of students SMPN 2 Bogor.
\end{abstract}

Keywords: Attachment Parents, Independence Teenagers 


\section{PENDAHULUAN}

Remaja merupakan generasi penerus bangsa yang akan terlibat dalam pembangunan negeri di masa yang akan mendatang. Suatu negara membutuhkan remaja yang berkualitas baik untuk membangun negara tersebut. Masa remaja sering disebut juga sebagai masa transisi yang mana pada masa ini remaja mengalami masa yang penuh gejolak dalam rangka mencari identitas diri, baik hal yang positif ataupun negatif (Ali M, 2014). Rata-rata, remaja mengalami metamorfosis yang tidak jelas, sehingga sikap diri mereka cenderung labil dan berubah-ubah. Kelabilan yang terjadi pada diri mereka, harus diperhatikan dengan baik, karena nantinya akan berpengaruh pada kemandirian diri remaja itu sendiri.

Pada masa remaja individu akan mengalami transisi perkembangan dari masa kanak-kanak ke masa dewasa, yang mengakibatkan perubahan-perubahan secara biologis, kognitif, dan sosioemosional, Salah satu aspek yang harus tercapai dalam masa perkembangan remaja adalah kemandirian.

Kemandirian pada masa remaja lebih bersifat psikologis seperti adanya tanggung jawab, percaya diri, membuat keputusan sendiri, dan kebebasan berprilaku sesuai dengan keinginannya. Sejalan dengan tuntutan agar remaja memiliki kemandirian yang baik, masih ada siswa yang memiliki pribadi tidak percaya diri ketika disekolah.

SMPN 2 Bogor merupakan salah satu SMP favorit di Kota Bogor. Hasil presentase pengamatan peneliti tentang percaya diri dari 945 orang siswa, hanya 2,8 persen saja yang aktif dalam organisasi seperti OSIS/MPK. Kemudian 97,2 persen tidak aktif dalam organisasi OSIS/MPK.

Berdasarkan data yang dihimpun (antaranews.com) senin, 13 mei 2013, salah satu siswa kelas VIII SMPN 1 Kota Bogor berhasil mendapatkan medali emas dalam kompetensi International Exhibition of Young Invenstor (IEYI) yang dilaksanakan di Malaysia dengan karya ciptanya sepatu listrik anti pelecehan seksual. Dengan kasus ini terlihat ia memiliki rasa percaya diri yang tinggi dengan berani tampil untuk mengikuti kompetensi di luar sekolah. Prestasi sebenarnya dapat dicapai dengan mengembangkan kegiatan ekstrakulikuler disekolah, diperlukan untuk melatih tingkat kemandirian pada siswa.

Kemudian berdasarkan pengamatan yang dilakukan di kelas dari 70 orang siswa yang diamati dan berdasarkan tes tertulis mengenai pengetahuan mereka tentang pengertian kemandirian, diperoleh hasil bahwa kemampuan memahami mengenai kemandirian sudah bagus, tetapi dalam pengapliksiannya masih kurang, terbukti $37 \%$ siswa mengaku masih menyontek ketika diadakannya ulangan sikap ini menunjukan ketidak mandirian dan kurangnya rasa percaya diri karena mereka tidak percaya atas jawaban sendiri dan takut salah, selain tidak percaya diri ketika ulangan, terdapat rendahnya kemandirian dalam diri siswa SMP Negeri 2 Bogor.

Generasi yang kuat, kreatif dan solutif adalah harapan setiap masyarakat. Hal ini dapat dibentuk dengan memaksimalkan lapisan inti yaitu keluarga, Persepsi remaja terhadap pengasuhan orangtua berpengaruh pada keberhasilan akademis, moral, dan kemandirian Pengasuhan yang dilakukan oleh orangtua sepenuhnya akan membentuk ikatan emosional yang kuat antara orangtua dengan anakanya. Ikatan emosional tersebut kemudian terjalin sepanjang rentang kehidupan manusia yang disebut dengan kelekatan.

Kelekatan (Attachment) adalah sebuah hubungan timbal balik yang melibatkan ikatan emosional antara anak dengan pengasuhnya. Menurut Armsden dan Greenberg (dalam Barrocas, 2009); macammacam kualitas kelekatan antara lain adalah: komunikasi, kepercayaan, dan keterasingan. salah satu contoh yang mempengaruhi adalah kepercayaan. Kepercayaan dapat muncul saat hubungan terjalin dengan kuat. Kepercayaan pada figur merupakan proses pembelajaran yang akan muncul setelah adanya pembentukan rasa aman melalui pengalaman-pengalaman secara konsisten kepada individu.

Kualitas kelekatan dari bayi akan menjadi akar kepercayaan anak terhadap figur lekat sebagai sumber rasa aman. Setiap anggota keluarga didalamnya melakukan interaksi dengan anaknya melalui perhatian dan kepercayaan yang akan menimbulkan komunikasi yang baik bagi anak, melalui komunikasi yang baik orangtua dapat memahami apa yang diinginkan oleh anaknya, mereka dapat menjadi lebih mandiri dan bertanggung jawab, rendahnya komunikasi yang terjalin antara orangtua dengan anak remaja dapat mengakibatkan perilaku menyimpang karena mereka merasa terasingkan oleh anggota keluarga. 
Anak akan merasa dirinya berarti ketika orangtua melakukan kontak yang baik. Begitupula komunikasi yang berlangsung didalam keluarga.

Orangtua tidak hanya mendengarkan ketika berkomunikasi dengan anak, melainkan memberikan respon yang baik dan saling tatap muka agar anak akan merasa dirinya berharga. Rendahnya kemandirian yang dialami siswa terlihat dari kurangnya kepecayaan, komunikasi, dan perilaku keterasingan yang diberikan oleh orangtua, sehingga anak masih bergantung kepada orang tua, untuk itu peneliti tertarik mengambil variabel kemandirian, karena siswa di tingkat SMP Merupakan awal dari perkembangan remaja yang merupakan masa peralihan dari tahap kanak-kanak yang perlahan mulai ditinggalkan menuju ke tahap dewasa yang belum dijalani. Untuk itu penulis melakukan penelitian dengan judul "Hubungan kelekatan orangtua terhadap kemandirian remaja".

Berdasarkan latar belakang masalah tersebut, maka permasalahan dapat diidentifikasikan sebagai berikut: 1) Kurangnya rasa percaya diri yang dimiliki oleh siswa SMPN 2 Kota Bogor; 2) Ketergantungan siswa SMPN 2 Kota Bogor terhadap orangtua dalam kebutuhan sehari-hari; 3) Kurangnya komunikasi yang terjalin siswa SMPN 2 Kota Bogor dengan orangtua.; 4) Kurangnya kepercayan orangtua terhadap siswa SMPN 2 Kota Bogor; 5) Adanya rasa keterasingan yang dirasakan anak dari orangtua.

Berdasarkan latar belakang dan identifikasi masalah, maka masalah penelitian dirumuskan sebagai berikut: Adakah hubungan antara kelekatan orangtua dengan kemandirian remaja?

Sesuai dengan rumusan masalah di atas, maka tujuan dalam penelitian ini adalah: 1) Menambah khasanah penelitian di Program Studi Pendidikan Kesejahteraan Keluarga yang berhubungan dengan kelekatan orangtua dalam kemandirian remaja; 2) Agar menjadi acuan sebagai penyelesaian masalah serupa kedepannya. Kemudian diharapkan agar terus melakukan ke masyarakat melalui instansi terkait hubungan tingkat kelekatan orangtua terhadap kemandirian remaja; 3) Diharapkan dapat menjadi bahan pertimbangan serta acuan untuk penelitian - penelitian sejenis di masa yang akan datang.

\section{METODOLOGI PENELITIAN}

Metode yang akan digunakan pada penelitian ini adalah metode penelitian survey melalui pendekatan korelasi, karena peneliti melakukan penelitian di sekolah dengan siswa sebagai respondennya dan peneliti menggunakan alat ukur kuesioner untuk mendapatkan data sebagai hasil penelitian. Hal ini sesuai dengan pernyataan sugiono (2008:12) bahwa metode survey ialah metode yang digunakan untuk mendapatkan data dari tempat tertentu yang alamiah (bukan buatan), tetapi peneliti melakukan pengumpulan data dengan menyebarkan kuesioner. Penelitian dengan metode survey termasuk kedalam metode pendekatan kuantitatif. Menurut sugiyono (2008:14) metode penelitian kuantitatif dapat diartikan sebagai metode penelitian yang berlandaskan pada filsafat positif, penelitian kuantitatif digunakan untuk meneliti populasi atau sampel tertentu. Kelompok akan dibentuk oleh peneliti, dimana kelompok tersebut adalah sampel siswa/siswi kelas VIII SMP Negeri 2 Bogor.

Populasi dalam penelitian ini ditetapkan remaja awal (12-15 tahun) yang tergolong kedalam siswa usia sekolah kelas VIII SMP Negeri 2 Bogor. Jumlah keseluruhan populasi tersebut adalah 310 siswa. Terdiri dari kelas VIII - A sampai dengan VIII - I. Alasan dipilihnya populasi siswa usia sekolah VII dikarenakan merupakan usia remaja dalam masa peralihan dari kanak-kanak menuju dewasa dan dalam tahap mencari jati.

Teknik pengambilan sampel yang digunakan dalam penelitian ini adalah teknik random sampling (teknik acak sederhana). Hasil pengambilan sampel penelitian ini sebanyak 175 orang.

\section{HASIL DAN PEMBAHASAN}

Berdasarkan penelitian yang telah dilakukan, diketahui nilai koefisien korelasi $r=0,148$ dan thitung $(1,980)>$ ttabel $(1,975)$. sehingga dapat disimpulkan bahwa terdapat hubungan positif yang signifikan kelekatan orangtua dengan kemandirian remaja. Adanya hubungan yang positif pada kelekatan orangtua dengan kemandirian remaja memang sejalan dengan apa dikatakan Monks (2006:10) kelekatan adalah 
mencari dan mempertahankan kontak dengan orang-orang yang tertentu saja. Orang pertama yang dipilih anak dalam kelekatan adalah ibu (pengasuh), ayah atau saudara-saudara dekatnya. Sedangkan menurut Santrock (2007: 36), kelekatan adalah ikatan emosional yang erat diantara dua orang. Kelekatan ini

mengacu pada suatu relasi antara dua orang yang memiliki perasaan yang kuat satu sama lain dan melakukan banyak hal bersama untuk melanjutkan relasi itu.

Orangtua berfungsi sebagai tokoh kelekatan dan sistem pendukung yang penting ketika remaja masuk kedalam dunia sosial yang lebih luas, negosiasi sehari-hari dapat memiliki dampak positif bagi perkembangan kemandirian remaja (Santrock, 2012:445).

Berdasarkan besaran korelasinya, penelitian ini sendiri masuk dalam kategori sangat lemah. Kelekatan orangtua memiliki sumbangan sebesar 0,0221atau 2,21\% dengan kemandirian remaja, sehingga semakin tinggi kelekatan orangtua maka semakin tinggi pula kemandirian remaja. Demikian sebaliknya semakin rendah kelekatan orangtua maka semakin rendah pula kemandiriannya. Adapun hal tersebut didukung pendapat yang dikemukakan oleh Joseph De Vito (2009) bahwa dalam kemampuan berkomunikasi terdapat aspek-aspek dalam memahami orang lain, apa yang memotivasi mereka, dan perasaan empati yang ada kaitannya dengan kemandirian. Komunikasi merupakan kunci semua aspek dalam keluarga, termasuk dalam membangun emosi anak.

Berdasarkan uraian diatas, maka dapat disimpulkan bahwa peran orang tua sangat dominan dalam proses perkembangan kemandirian remaja di SMPN 2 Bogor. peran pengasuhan orangtua bagi remaja berpengaruh pada keberhasilan akademis, moral, dan kemandirian. (Kim \& Gim Chung, 2003). Pengasuhan yang dilakukan oleh orangtua sepenuhnya akan memenuhi ikatan emosional yang kuat antara orangtua dengan anaknya. Ikatan emosional tersebut kemudian terjalin sepanjang rentang kehidupan manusia yang di sebut dengan kelekatan. Menurut Bowlby, 2000, kelekatan adalah konstruk yang berlangsung rentang kehidupan yaitu dari bayi, masa kanak-kanak, remaja, hingga dewasa. Menurut Laursen (Santrock, 2012:444) Remaja didorong dan dibimbing untuk mandiri oleh orangtua agar dapat mengambil keputusan yang masuk akal.

Dari hasil penelitian dan perhitungan skor menunjukan rata-rata remaja pada SMPN 2 Bogor memiliki kelekatan keluarga yang cukup baik dan hasil skor kemandirian remaja yang hasilnya juga cukup baik. Berdasarkan uraian diatas, maka dapat disimpulkan bahwa peran orangtua berhubungan dalam proses perkembangan kemandirian remaja di SMPN 2 Bogor. Orang tua harus mampu membangun kelekatan yang baik seperti adanya kepercayaan, komunikasi, dan sikap tidak mengasingkan. Keberadaan para orangtua dirumah diharapkan menjadi orangtua seutuhnya yang tidak hanya berorientasi pada kecerdasan intelektual semata namun juga memperhatikan kelekatan antara orangtua dan remaja sehingga dapat membantu dalam perkembangan kemandirian remaja. Hal tersebut sangat penting karena kelekatan merupakan kunci semua aspek dalam keluarga, termasuk dalam membangun kemandirian anak.

\section{KESIMPULAN}

Berdasarkan perhitungan yang telah dilakukan didapatkan skor masing-masing responden, Kelekatan Orangtua memiliki dimensi tertinggi presentasenya atau yang paling dominan terdapat pada dimensi komunikasi dengan rata-rata skor 564,14 dan presentase sebesar $80,59 \%$ dan yang terlemah pada dmensi keterasingan dengan rata-rata skor 484 dan presentase sebesar $69,14 \%$. perhitungan kemandirian remaja di SMPN 2 Bogor memiliki dimensi tertinggi presentasenya atau yang paling dominan terdapat pada dimensi Independent belief dengan skor rata-rata 640,5 dan presentase sebesar $91,5 \%$. dan dimensi yang paling lemah yaitu dimensi yaitu self reliance presentase sebesar $52,53 \%$.

Perhitungan korelasi menunjukan rhitung $(r)=0,148$. Dengan demikian dapat disimpulkan bahwa hasil perhitungan yang diperoleh pada siswa/i SMPN 2 Bogor termasuk ke dalam kategori $0-0,199$ korelasi yang sangat rendah tetapi berhubungan positif antara variabel kelekatan orangtua dengan variabel kemandirian remaja remaja. Karena siswa/i SMPN 2 Bogor dalam keyakinan nilai semakin terbentuk menghormati kedua orangtua. hal ini disebabkan tingginya angka rata-rata skor per indikator pada dimensi independent belief yaitu sebesar 640,5 dan siswa/i SMPN 2 Bogor kelekatan orangtua dalam komunikasi 
yang baik. hal itu ditunjukkan dengan rhitung yang positif. Hasil koefisien determinasi presentase menunjukan bahwa kemandirian remaja 2,21\% ditentukan oleh kelekatan orangtua pada siswa/i SMP 2 Bogor.

\section{DAFTAR PUSTAKA}

Ali, Mohammad \& Asrori, Mohammad. 2014. Psikologi Remaja. Jakarta: Bumi Aksara.

Armsden, G., \& Greenberg, M. 2009. Inventori of parent and peer attachment (IPPA) manual. http://search.proquest.com. Diakses pada tanggal 20 desember 2016

Barrocas, A.L. 2009. Adolescent Attachment to Parents and Peers. http://www.marial.emory.edu/pdf/barocs. Tanggal akses 2 Januari 2017.

Bowlby, J. 1988. A secure base: parent-child attachment and healthy human development. Basic Books, Inc. New York.

Chaplin, J.P. 1989. Kamus Lengkap Psikologi. Rajawali Press. Jakarta.

Monks,S.J. 2006. Psikologi Perkembangan. Pengantar dalam berbagai bagian. Yogyakarta: Gajah Mada Univercity. Press.

Santrock, John W. 2003. Adolescence : Perkembangan Remaja, edisi Ke-6. Jakarta : Erlangga.

Santrock, John W. 2007 Perkembangan Anak . edisi Ke-11. Jakarta : Erlangga.

Santrock, Jhon W. 2012. Life-Span Development, edisi Ke-13. Jakarta : Erlangga.

Sugiyono. 2015. Metode Penelitian Kuantitatif Kualitatif dan R\&D. Alfabeta. Bandung.

Sugiyono. 2015. Metode Penelitian Bisnis. Alfabeta. Bandung

Sugiyono. 2009. Metode Penelitian Pendidikan. Alfabeta. Bandung 